International

Medical Society

http://imedicalsociety.org

\title{
Evaluation of Pulmonary Function and Body Composition in Pregnant Women

\begin{abstract}
Andréa Carla Brandão da Costa Santos ${ }^{1}$, Alex Sandro Rolland Souza ${ }^{2}$, Jousilene de Sales Tavares ${ }^{3}$, Melania Maria Ramos Amorim²
\end{abstract}

\section{Abstract}

Objectives: To compare the pulmonary function and the body composition between trimesters of pregnancy and, to determine the variables correlated to the peak expiratory flow (PEF) and the expiratory flow between $25 \%$ and $75 \%$ of vital capacity $\left(\mathrm{FEF}_{25 \% 75 \%}\right)$.

Methods: A cross-sectional study examined 120 healthy low-risk pregnant women in the three trimesters of pregnancy, measured by spirometry and multisegmental electrical impedance. Women between the fifth and 40th gestational week, ages between 18-35 years, singletons, and sedentary were included. Smokers, individuals with cardio-respiratory diseases, neurological and chest deformities were excluded. For data analysis, descriptive statistic was used to characterize the sample and analysis of variance for comparing the groups with post hoc Tukey test. The correlation between the independent variables and the flow was performed by Pearson correlation coefficient. Multiple linear regression was used to estimate the degree of relationship between the dependent and independent variables.

Results: The vital capacity, the expiratory volume in one second, the peak expiratory flow and expiratory flow between $25 \%$ and $75 \%$ of vital capacity decreased with the progression of pregnancy, but no significant statistically difference was found. An increase of the current weight $(p<0.02)$ and $\mathrm{BMI}(p<0.003)$, total body water $(p<0.04)$, extracellular water $(p<0.03)$, fat mass $(p<0.04)$ and fat-free mass $(p$ $<0.04)$ was observed during the gestational trimesters. There were correlations between $\mathrm{PEF}$ and $\mathrm{FEF}_{25 \% 75 \%}$ with some variables, such as maternal age, height, pre-pregnancy weight, total body weight and extracellular water, lean mass and fat-free mass. The multiple linear regression analysis showed that height and maternal age were
1 PhD Student at the Post-Graduate Program in Maternal-Infant Health, Instituto de Medicina Integral Professor Fernando Figueira (IMIP). Recife, PE, Brazil.

2 Professor PhD. Professor at the PostGraduate Program in Maternal-Infant Health, Instituto de Medicina Integral Professor Fernando Figueira, Recife, PE, Brazil.

3 Professor PhD in Maternal-Infant Health, Instituto de Medicina Integral Professor Fernando Figueira (IMIP), Recife, PE, Brazil. Instituto Paraibano de Pesquisa Professor Joaquim Amorim Neto (IPESQ), campina Grande, PB, Brazil

Contact information:

\section{Andréa Carla Brandão da Costa Santos.}

Address: Instituto de Medicina Integral Professor Fernando Figueira (IMIP), Rua dos Coelhos, 300, Recife, Pernambuco, 50070-550, Brazil.

Tel: (83) 98805-5162

Đandreabrandao@ibest.com.br 
associated with PEF, being responsible for explaining $14.7 \%$ of its variability. The pre- pregnancy weight explained $6.5 \%$ of the variability of the $\mathrm{FEF}_{25 \% 75 \%}$. The multiple linear regression analysis showed that height and maternal age were associated with PEF, explaining 14.7\% of its variability.

Conclusion: This study showed that the volumes and lung capacity in healthy pregnant women do not seem to change with the progress of pregnancy. The pre-pregnancy weight was related to the $\mathrm{FEF}_{25 \% 75 \%}$. Height and maternal age had greater influence on PEF changes, while the body composition and obstetric variables did not influence it.

\section{Keywords}

Pregnant; Pulmonary Function

Test; Body Composition.

\section{Introduction}

During pregnancy, the respiratory system goes through several adjustments resulting from hormonal and mechanical changes [1-4] due to hormones such as estrogen and progesterone, which predispose to changes in the upper airways mucosa, including increased vasodilation, edema, hyperemia and glandular hypersecretion [1, 3, 5]. Along with these changes occur adjustments to the ribcage, aiming to accommodate the expansion of the uterus that moves the diaphragm in cephalic direction in approximately $4 \mathrm{~cm}$. These changes are the expansion of the anteroposterior and transverse diameters of the chest, around $2 \mathrm{~cm}$, resulting in increase of 5 to 7 $\mathrm{cm}$ in the lower chest circumference [1,5].

As a result of these changes, there are adjustments in lung volumes and capacities between the $8^{\text {th }}$ and 10th gestational week, peaking around the $37^{\text {th }}$ week $[2,5]$. It is observed a reduction of expiratory reserve volume (ERV) from $15 \%$ to $20 \%$ and from $20 \%$ to $25 \%$ of residual volume (RV), which results in a decreased functional residual capacity (FRC) of $10 \%$ to $25 \%[1,3,5,6]$. Regarding the static lung volumes, studies show that the inspiratory capacity (IC) increases by approximately $5 \%$ to $10 \%$ resulting from the expansion of the diaphragmatic incursion
$[1,5,7-9]$. This stems from reduced compliance of the lower chest wall along with the elevation of the diaphragm [1, 6], leading to a small increase or preservation of vital capacity (VC) [1, 3, 6-9].

It was noted also that progesterone levels stimulate the respiratory center with increased respiratory drive $[1-3,6,7]$. The minute volume (MV) increases $20 \%$ to $50 \%$ resulting from the increase of $30 \%$ to $50 \%$ in the tidal volume (VT) and respiratory rate (RR), which increases about two breaths per minute $[1,3,6]$. Several studies have addressed the airflow mechanics during pregnancy using spirometry. It was observed that the forced vital capacity (FVC) and forced expiratory volume in one second $\left(\mathrm{FEV}_{1}\right)$ show no significant change [4, 7-10] and peak expiratory flow (PEF) is unchanged or slightly decreased during the pregnancy [11, 12].

It seems plausible to consider that progressive gestational changes in the shape and configuration of the abdomen, diaphragm and chest, besides maternal weight gain could compromise lung function during pregnancy. However, most studies establish the influence of age, height and race in changes of lung function [12-14]. Moreover, other studies have shown that body composition may also influence it $[10,12,15]$. 
Despite all that has been exposed, studies that report the influence of anthropometric, obstetric and body composition variables in lung function in a literature review performed in the databases of PubMed/MEDLINE between the years 1970-2016 were scarce, beyond not encompassing the trimesters of pregnancy and reference values for pregnant population were not found.

Therefore, this study aims to describe and compare the pulmonary function and body composition between trimesters of pregnancy and to determine the variables correlated to peak expiratory flow (PEF) and expiratory flow between $25 \%-75 \%$ of forced vital capacity $\left(\mathrm{FEF}_{25 \% 75 \%}\right)$.

\section{Methods}

A cross-sectional study examined 120 low-risk pregnant women between the fifth and 40th gestational week. The study was developed in the Physical Evaluation Laboratory at the University Centro Universitário de João Pessoa (UNIPÊ)- Paraiba/Brazil from November 2015 to May 2016.

Women ages between 18-35 years, singletons, low risk, in the three trimesters of pregnancy and sedentary were included. Those subjects that were unable to undergo the impedance analysis or evaluation of lung or cardiac function or had been diagnosed with a neuromuscular disease, a deformity of the ribcage or presence of metallic devices, such as cardiac pacemakers and smokers were excluded.

For the sample characterization, variables such as maternal age, height, pre-pregnancy weight and body mass index (BMI), gestational age, trimester of pregnancy and fundal height (FH) were collected.

The variables of lung function studied were: forced vital capacity (FVC) and forced expiratory volume in one second $\left(\mathrm{FEV}_{1}\right)$ expressed in liters $(\mathrm{I})$, expiratory flow between $25 \%$ and $75 \%$ of forced vital capacity $\left(\mathrm{FEFV}_{25 \% 75 \%}\right)$ and peak expiratory flow (PEF) expressed in liters per second (I/S) and maximum voluntary ventilation (MVV) expressed in liters per minute (I/min).
The body composition was assessed using the current weight $(\mathrm{kg})$ and $\mathrm{BMI}\left(\mathrm{kg} / \mathrm{m}^{2}\right)$, body fat mass, lean mass and fat-free mass expressed in kilograms, total body water (TBW) and extracellular water (ECW ) expressed in liters (I).

The measurement of the fundal uterine height (FU) was performed with the pregnant woman in the supine position with uncovered abdomen and lower limbs extended. The initial end of the flexible and inelastic tape was attached to the top edge of the pubic symphysis, passing it between the index and middle fingers until the cubital edge of the hand reaches the fundus of the uterus [16].

The height was measured by a stadiometer (Standard Sanny ${ }^{\circledR}$ - ES 2030- São Paulo, Brazil). For the evaluation, a pregnant woman wore light clothing and was barefoot with heels together and arms relaxed along the body. She was instructed to remain as upright as possible, with the head directed vertically and to take a deep breath at the time of measurement. [17, 18].

The assessment of the body composition was done by Bioelectrical impedance analysis (BIA) (InBody $720^{\circledR}$, BSM-230, Seoul, Korea), which uses the direct segmental multi frequency measurement method, through the quadrupole electrode system with eight tactile points - two points on each foot and two in each hand. The measurement of the impedance value of each body segment (right and left arms, trunk, left and right legs) uses the frequencies of $1 \mathrm{KHz}, 5 \mathrm{KHz}, 50 \mathrm{KHz}, 250 \mathrm{kHz}$, and $500 \mathrm{KHz} 1,000$ $\mathrm{KHz}$ [19].

To perform the test, the environment remained with temperature between $23 \mathrm{C}^{\circ}$ and $25 \mathrm{C}^{\circ}$ and women were required to a minimum fasting of $4 \mathrm{~h}$, to not practice exercise, to wear shorts or lycra pants with top. It was also required that they used the toilet in order to reduce the volume of urine and faeces, as well as remove all the trappings of metals. At the time of measurement, the volunteer was positioned standing on the basis of equipment and centrally on the electrodes, holding the handpie- 
ces and, keeping slightly open and relaxed arms for about 4 minutes [20].

After assessment of the body composition, the pregnant woman was invited to have lunch and wait about 10 minutes to then be submitted to the evaluation of the PEF with a spirometer (KoKo ${ }^{\circledR}$ Spirometer, Fleisch-type, Colorado, USA). The assessment took into account the standards guided by the American Toracic Society (ATS). The spirometer was calibrated before each test and the temperature remained around $23^{\circ} \mathrm{C}$ to $25^{\circ} \mathrm{C}$. The test was repeated at least three times and a maximum of eight to ensure the understanding of the participant, for which the value of the analyzed parameters could not exceed $10 \%$ of each measure accepted and the best of the three curves was selected. The procedures were carefully described in order to avoid leakage around the mouth and furthermore, a nose clip was used to prevent leakage of air through the nose [21].

For the examination, the participants remained seated, keeping upright chest and the head in a neutral position. After some quiet breathing cycles, it was requested a maximum oral inspiration followed by a brief apnea and, soon after, the maximum sustained huffing up maneuver until the capacity of the pregnant woman, for at least six seconds, measuring the forced vital capacity (FVC). From this parameter, the system calculated the PEF. It was given a two minute interval between measurements to provide more rest [21, 22].

Data analysis was performed using descriptive statistics with calculation of measurements of central tendency (mean) and of dispersion (standard deviation), for the number and proportion variables, for categorical variables to characterize the obstetric and, anthropometric profile of pregnant women. The Kolmogorov-Smirnov test was used to verify the normality of the data. The comparison of means between groups was performed by the unpaired Student's t-test. The Pearson correlation test was used to verify possible correlations between varia- bles. The multiple linear regression model was built

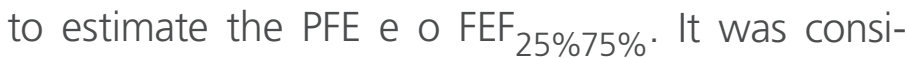
dered a $10 \%$ significance level for the entry of the variables in the model, withdrawing subsequently all those not persisted associated with a significance level of $5 \%$.

The study was approved by the Human Research Ethics Committee (HREC) of the University UNIPÊ under the CAAE: 50141215.9.0000.5176. All pregnant women voluntarily agreed to participate and signed an Informed Consent Form (ICF).

\section{Results}

Data from 120 pregnant were analyzed, being 14 $(11.7 \%)$ of the first trimester, $74(61.7 \%)$ of the second and 32 (26.7\%) of the third trimester of pregnancy (Table 1). Figure 1 depicts the flowchart recruitment of volunteers enrolled in the study.

Figure 1: Flowchart of recruitment of the volunteers included in the study.

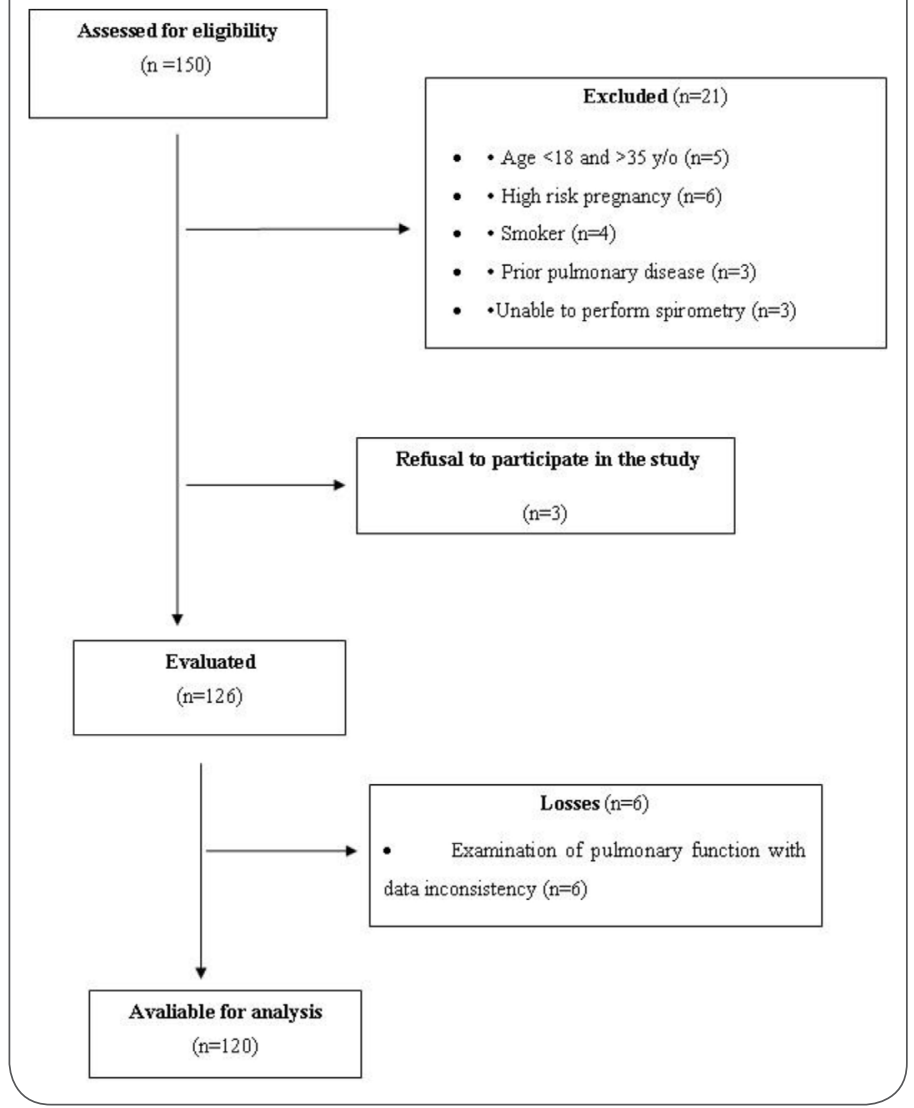


Table 1. Baseline characteristics of pregnant women by gestational trimester

\begin{tabular}{|c|c|c|c|c|}
\hline Variables & $\begin{array}{c}1 s t \\
\text { trimester } \\
\mathrm{X} \pm \mathrm{SD} \\
\mathrm{N}=14\end{array}$ & $\begin{array}{c}\text { 2nd } \\
\text { trimester } \\
\begin{array}{c}\mathrm{X} \pm \mathrm{SD} \\
\mathrm{N}=74\end{array}\end{array}$ & $\begin{array}{c}\text { 3rd } \\
\text { trimester } \\
\mathrm{X} \pm \mathrm{SD} \\
\mathrm{N}=32\end{array}$ & $p^{a}$ \\
\hline $\begin{array}{l}\text { Maternal Age } \\
\text { (years) }\end{array}$ & $28.0 \pm 5.3$ & $27.7 \pm 4.5$ & $27.8 \pm 4.1$ & 0.97 \\
\hline Height (cm) & $162.8 \pm 5.6$ & $162.3 \pm 5.9$ & $161.8 \pm 6.0$ & 0.84 \\
\hline $\begin{array}{l}\text { Pre-pregnancy } \\
\text { Weight (Kg) }\end{array}$ & $61.0 \pm 9.1$ & $64.5 \pm 12.5$ & $63.2 \pm 9.8$ & 0.56 \\
\hline $\begin{array}{l}\text { Pre-pregnancy } \\
\mathrm{BMI}\left(\mathrm{Kg} / \mathrm{m}^{2}\right)\end{array}$ & $23.1 \pm 2.9$ & $24.4 \pm 4.3$ & $24.1 \pm 3.2$ & 0.49 \\
\hline $\begin{array}{l}\text { Gestational age } \\
\text { (weeks) }\end{array}$ & $12.0 \pm 1.2$ & $21.3 \pm 4.1$ & $31.7 \pm 2.7$ & $<0.001$ \\
\hline $\begin{array}{l}\text { Fundal Height } \\
\text { (cm) }\end{array}$ & $10.8 \pm 1.6$ & $19.8 \pm 4.1$ & $29.9 \pm 2.5$ & $<0.001$ \\
\hline
\end{tabular}

As for the evaluated volumes and lung capacities,

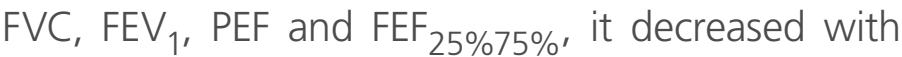
the progression of pregnancy with no statistically significant difference (Table 2).

With the progression of the pregnancy, the body composition showed changes in all parameters, these being statistically significant. The multiple comparison test of Tukey showed that the current weight,

Table 2. Parameters of lung function by spirometry among the group of pregnant women by gestational trimester.

\begin{tabular}{|c|c|c|c|c|}
\hline Variables & $\begin{array}{c}1 s t \\
\text { trimester } \\
\mathrm{X} \pm \mathrm{SD}\end{array}$ & $\begin{array}{c}\text { 2nd } \\
\text { trimester } \\
\text { X土SD }\end{array}$ & $\begin{array}{c}\text { 3rd } \\
\text { trimester } \\
\text { X } \pm \text { SD }\end{array}$ & $p^{a}$ \\
\hline $\mathrm{FVC}(\mathrm{I})$ & $3.34 \pm 0.5$ & $3.40 \pm 0.5$ & $3.31 \pm 0.5$ & 0.63 \\
\hline FEV1 & & & & \\
\hline PEF (I/seg) & $5.42 \pm 1.4$ & $5.44 \pm 1.1$ & $5.40 \pm 1.3$ & 0.98 \\
\hline $\begin{array}{l}\text { FEF25\%75\% } \\
\text { (I/seg) }\end{array}$ & $3.35 \pm 0.6$ & $3.28 \pm 0.7$ & $3.16 \pm 0.8$ & 0.63 \\
\hline MVV (I/min) & $94.93 \pm 15.8$ & $96.14 \pm 17.9$ & $95.5 \pm 16.0$ & 0.96 \\
\hline
\end{tabular}

FVC: Forced vital capacity; FEV1: Forced expiratory volume in one second; PEF: Peak expiratory flow FEF25\%75\%: Expiratory flow between 25\%-75\% of FVC; MVV: Maximum voluntary ventilation. X: Mean; SD: Standard deviation. a: ANOVA.
TBW, ECW, lean mass and fat-free mass demonstrated difference between the first and third trimesters $(p=0.02 ; p=0.04 ; p=0.02 ; p=0.04 ; p=0.04$, respectively), while the current BMI $(p=0.02 ; p=0.002)$ and fat mass ( $p=0.05, p=0.04$ ) showed differences between the $2^{\text {nd }}$ and $3^{\text {rd }}$ quarters as compared with the first one (Table 3).

Table 3. Body composition parameters assessed by bioelectrical impedance between the group of pregnant women by trimester.

\begin{tabular}{|c|c|c|c|c|}
\hline Variables & $\begin{array}{c}\text { 1st } \\
\text { trimester } \\
\text { X土SD }\end{array}$ & $\begin{array}{c}\text { 2nd } \\
\text { trimester } \\
\text { X } \pm \text { SD }\end{array}$ & $\begin{array}{c}\text { 3rd } \\
\text { trimester } \\
\text { X } \pm \text { SD }\end{array}$ & $p^{a}$ \\
\hline $\begin{array}{l}\text { Current weight } \\
(\mathrm{Kg})\end{array}$ & $62.0 \pm 8.3$ & $69.7 \pm 12.6$ & $72.5 \pm 10.9^{1}$ & 0.02 \\
\hline $\begin{array}{l}\text { Current BMI } \\
\left(\mathrm{Kg} / \mathrm{m}^{2}\right)\end{array}$ & $23.3 \pm 2.6$ & $26.4 \pm 4.31$ & $27.7 \pm 3.6^{1}$ & 0.003 \\
\hline $\operatorname{TBW}(\mathrm{I})$ & $30.2 \pm 4.1$ & $32.1 \pm 4.1$ & $35.5 \pm 4.2^{1}$ & 0.04 \\
\hline $\mathrm{ECW}(\mathrm{I})$ & $11.6 \pm 1.5$ & $12.4 \pm 1.6$ & $12.9 \pm 1.5^{1}$ & 0.03 \\
\hline Fat mass (Kg) & $20.7 \pm 4.4$ & $25.8 \pm 8.41$ & $26.8 \pm 6.1^{1}$ & 0.04 \\
\hline Lean mass (Kg) & $38.8 \pm 5.3$ & $41.2 \pm 5.3$ & $42.9 \pm 5.4^{1}$ & 0.05 \\
\hline $\begin{array}{l}\text { Fat-free mass } \\
(\mathrm{Kg})\end{array}$ & $41.2 \pm 5.6$ & $43.9 \pm 5.6$ & $45.7 \pm 5.8^{1}$ & 0.04 \\
\hline
\end{tabular}

TBW: Total body water; ECW: Extracellular water; X: Mean; SD: Standard deviation. a. ANOVA. 1: Significant difference of the first quarter, $p<0.05$ (Tukey test).

When correlating $\mathrm{PEF}$ and $\mathrm{FEF}_{25 \% 75 \%}$ with the independent variables, it was observed weak correlations, however significant. A positive and significant correlation was found between maternal age, height, pre-pregnancy weight, TBW, ECW, lean mass and fat-free mass with PEF. Furthermore, the pre-pregnancy weight, current weight, TBW, ECW, fat mass, lean mass and, fat-free mass were correlated positively and significantly with $\mathrm{FEF}_{25 \% 75 \%}$ (Table 4).

Through multiple linear regression analysis, it was showed that height and maternal age were independently associated with PEF, being responsible for explaining $14.7 \%$ of its variability, reflected by the following equation: PFE $=-5.462+0.055 \times$ height 
Table 4. Correlation of $\mathrm{PEF}$ and $\mathrm{FEF}_{25 \% 75 \%}$ with independent variables.

\begin{tabular}{|c|c|c|c|c|c|}
\hline \multirow{3}{*}{$\begin{array}{l}\text { Independent } \\
\text { variables }\end{array}$} & \multirow{3}{*}{$X \pm S D$} & \multicolumn{4}{|c|}{ Dependent variables } \\
\hline & & \multicolumn{2}{|c|}{ PEF (I/seg) } & \multicolumn{2}{|c|}{$\begin{array}{c}\text { FEF }_{25 \% 75 \%} \\
(\mathrm{I} / \mathrm{sec})\end{array}$} \\
\hline & & r & $p^{a}$ & $r$ & $p^{a}$ \\
\hline Age (years) & $27.8 \pm 4.4$ & 0.267 & 0.003 & 0.065 & 0.48 \\
\hline Height (cm) & $162.2 \pm 5.8$ & 0.277 & 0.002 & 0.160 & 0.08 \\
\hline $\begin{array}{l}\text { Pre-pregnancy } \\
\text { weight }(\mathrm{Kg})\end{array}$ & $63.8 \pm 11.5$ & 0.187 & 0.04 & 0.254 & 0.00 \\
\hline $\begin{array}{l}\text { Current } \\
\text { weight }(\mathrm{Kg})\end{array}$ & $69.6 \pm 12.0$ & 0.142 & 0.12 & 0.223 & 0.02 \\
\hline GA (weeks) & $22.9 \pm 6.9$ & -0.073 & 0.43 & -0.099 & 0.28 \\
\hline $\mathrm{FH}(\mathrm{cm})$ & $21.5 \pm 6.8$ & -0.036 & 0.69 & -0.055 & 0.55 \\
\hline TBW (I) & $32.2 \pm 4.2$ & 0.206 & 0.02 & 0.219 & 0.02 \\
\hline ECW (I) & $12.4 \pm 1.6$ & 0.184 & 0.05 & 0.190 & 0.04 \\
\hline Fat mass (Kg) & $25.5 \pm 7.7$ & 0.071 & 0.44 & 0.192 & 0.04 \\
\hline Lean mass (Kg) & $41.4 \pm 5.4$ & 0.200 & 0.03 & 0.210 & 0.02 \\
\hline $\begin{array}{l}\text { Fat-free mass } \\
(\mathrm{Kg})\end{array}$ & $44.0 \pm 5.8$ & 0.202 & 0.03 & 0.209 & 0.02 \\
\hline
\end{tabular}

Table 5. Multiple linear regression model for the peak expiratory flow (PEF).

\begin{tabular}{l|c|c|c|c|}
\multirow{2}{*}{\multicolumn{1}{c}{ PEF }} & \multicolumn{2}{|c|}{ Initial model* } & \multicolumn{2}{c|}{ Final model* } \\
\cline { 2 - 6 } & Coefficient & $\boldsymbol{p}$ & Coefficient & $\boldsymbol{p}$ \\
\hline Maternal age & 0.070 & 0.002 & 0.070 & 0.002 \\
\hline Height & 0.055 & 0.002 & 0.055 & 0.002 \\
\hline $\begin{array}{l}\text { Pre-pregnancy } \\
\text { weight }\end{array}$ & 0.048 & 0.62 & - & - \\
\hline TBW & -0.032 & 0.78 & - & - \\
\hline ECW & -0.067 & 0.56 & - & - \\
\hline Fat mass & -0.038 & 0.73 & - & - \\
\hline Fat-free mass & -0.038 & 0.74 & - & - \\
\hline R 2 & & $14.7 \%$ &
\end{tabular}

TBW: Total body water; ECW: Extracellular water. * ANOVA Test: $p<0.001$
$+0.070 \times$ age. On the other hand, the pre-pregnancy weight was independently associated with

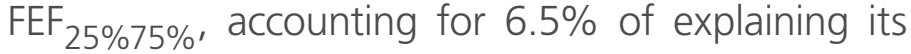
variability, resulting in the equation: $\mathrm{FEF}_{25 \% 75 \%}=$ $2.268+0.016 \times$ pre-pregnancy weight (Tables 5 and 6).

Table 6. Multiple linear regression model for expiratory flow between $25 \%-75 \%$ of forced vital capacity $\left(\mathrm{FEF}_{25 \% 75 \%}\right)$.

\begin{tabular}{|l|c|c|c|c|}
\hline \multirow{2}{*}{ FEF $_{25 \% 75}$} & \multicolumn{2}{|c|}{ Initial model* } & \multicolumn{2}{c|}{ Final model* } \\
\cline { 2 - 5 } & Coefficient & $\boldsymbol{p}$ & Coefficient & $\boldsymbol{p}$ \\
\hline $\begin{array}{l}\text { Pre-pregnancy } \\
\text { weight }\end{array}$ & 0,016 & 0,005 & 0,016 & 0,005 \\
\hline Current weight & $-0,071$ & 0,75 & - & - \\
\hline TBW & 0,058 & 0,67 & - & \\
\hline ECW & $-0,011$ & 0,94 & - & - \\
\hline Lean mass & 0,032 & 0,82 & - & - \\
\hline Fat mass & $-0,103$ & 0,56 & - & - \\
\hline Fat-free mass & 0,030 & 0,83 & - & - \\
\hline R 2 & & $6,5 \%$ & & \\
\hline
\end{tabular}

TBW: Total body water; ECW: Extracellular water. * ANOVA Test: $p<0.001$

\section{Discussion}

The study suggests that as the pregnancy progresses, the values of FVC, FEV $1, \mathrm{PEF}_{1} \mathrm{FEF}_{25 \% 75 \%}$ and MVV in healthy pregnant women do not change. However, the variables of body composition (weight, BMI, TBW, ECW, fat mass, lean mass and fat-free mass) showed a significant increase. The height and maternal age have greater influence on PEF changes, while the pre-pregnancy weight influences $\mathrm{FEF}_{25 \% 75 \% \text {. }}$

In the current study, FVC, FEV 1 , PEF and $\mathrm{FEF}_{25 \% 75 \%}$ showed no statistically significant change. These results are grounded in a pertinent literature $[3,4,7]$ and have biological plausibility because of hormonal changes such as elevation of progesterone and estrogen and, mechanical changes such as enlarge- 
ment of the lower chest, elevation of the last ribs and diaphragm allowing an adjustment in breathing function to meet the demands of the mother and fetus without causing repercussions during the gravid state.

Our findings show that the assessed respiratory parameters were reduced during the trimesters of pregnancy, but without statistical significance. It is believed that these results may be related to mechanical adjustments imposed by pregnancy, in addition to hormonal changes that provide bronchodilation and facilitate the passage of the airflow.

A cross-sectional study that evaluated fifty pregnant women in the three trimesters of pregnancy and two months after delivery observed that there was no change in FVC and FEV 1 [8]. Another study evaluated lung function by spirometry flow in 51 pregnant women compared with 40 non-pregnant women paired by age. The parameters FVC, FEV 1 , $\mathrm{FEF}_{25 \% 75 \%}$ showed no significant change during pregnancy [10], which may be justified by an adaptation of the maternal respiratory system during pregnancy and mechanical influences caused by the elevation of the uterus and enlargement of the rib cage. These studies despite comparing pregnant women with a control group of non-pregnant women showed a small sample. Maybe that's why the results were similar when compared to the current study, since the addressed sample was 120 pregnant women distributed in the three trimesters of pregnancy.

Whereupon, it is observed that during a healthy pregnancy there is no imposition for the passage of the airflow reflecting in maintenance of the ventilatory parameters, results envisioned in this study. The hormonal influence, especially by the action of progesterone in the bronchi, allows that the airway conductance remain in normal state, thus resulting in pervious roads, imposing no change in $\mathrm{FEV}_{1}$ or FVC $[2,3,23]$.

Several cross-sectional and longitudinal studies [7, $10,24]$ have been conducted showing results that support this research, in which there were no changes in the evaluated respiratory parameters. It is suggested that these responses are due to changes in bronchial tonus, as well as the accommodation of the ribcage with the elevation of the uterus and therefore of the diaphragm, allowing volumes and capacities to remain with little or no modification, since the mechanical changes will be adjusting to the development of the pregnancy cycle.

In our observations, the PEF average values were also reduced when compared during the trimesters of pregnancy, although not statistically significant. Similar results were found in other studies $[12,13$, 25]. It is noticed that these changes may be related to body weight gain during pregnancy and mechanical factors that cause restriction in diaphragmatic incursion, thus decreasing the FVC. Nevertheless, the hormonal action, especially of the progesterone, promotes bronchial dilation reducing airway resistance without bringing impact on pulmonary function.

It was also possible to notice that some studies showed different results of the current research with changes in FVC and PEF statistically significant. A longitudinal study followed sixty pregnant women during the three trimesters of pregnancy and ten weeks after delivery, observing a reduction of the PEF by comparing pregnant and non-pregnant women values. The authors suggest that the increase of the abdomen provides reduction in force of contraction of the abdominal and inner intercostal muscles, leading to a decrease in the output air speed, since the PFE is a dependent effort maneuver [13].

We believe that our research has revealed different results due to the study type, which was cross-sectional, and to the non-involvement of a control group of non-pregnant women. With this control group, it would be expected to find differences, since the gravid state imposes mechanical and hormonal adjustments to suit the mother and the fetus needs. 
Another cross-sectional study evaluated 150 pregnant women, 50 in each trimester and compared with 50 non-pregnant women aged between 1935 years. There was a decrease in PEF in the three quarters when compared to the control group [26]. Thus, it can be explained that the study design did not affect the result, but the presence of a control group of non-pregnant women did.

Given the above, coupled with the fact that studied respiratory parameters do not show changes, it is suggested that the morphological, physiological and mechanical adaptations of the respiratory system minimize the progressive changes in the form and abdomen configuration, chest and diaphragm wall, thereby, maintaining adequate ventilation without repercussions for mother and fetal growth.

In the present study, differences in body composition were observed when comparing pregnant women between the trimesters. There was a statistically significant increase in the average values of the current weight, current BMI, TBW, ECW, fat mass, lean mass and fat-free mass. These results can be explained due to the increase in body weight with the advancement of pregnancy resulting from the growing fetus, the pregnant woman's weight gain, as well as the expansion of blood volume, wherein the TBW rises approximately from 5 to 8 liters in a term pregnancy [27] to suit the demands of the gravid state and to not compromise fetal growth [28, 29].

In a study that evaluated 170 healthy pregnant women, ages 22-44 years old during the gestational trimesters using analysis by quadrupole bioelectrical impedance analysis (BIA), it was observed an increase of the body weight, TBW, ECW, intracellular water (ICA) with progression of pregnancy, demonstrating that the fat deposition and increased fluid retention appear to be responsible for the pregnancy weight gain [34]. To evaluate the ECW and TBW behavior during pregnancy, 63 women were evaluated using the BIA and accompanied during the trimesters of pregnancy. Fifty women had a normal pregnancy and 13 had hypertension during pregnancy. There was a significant increase in the TBW and ECW in the healthy pregnant women, while in the hypertensive pregnant women group there was a decrease with the unfolding of the pregnancy, reflecting in poor hemodynamic adaptation [31], showing that the monitoring of these parameters can help to control high blood pressure.

In our research, we observed that the body composition of pregnant women rose during the trimesters, but it remained within the normal range [27]. Studies show that overweight and obesity during pregnancy can have a negative effect, predisposing the onset of asthma, hypertension, diabetes, among other complications [27, 28, 32]. These findings confirm the importance of pregnant women to maintain healthy lifestyle habits such as: proper nutrition, physical activity-oriented by a health professional to preserve the normal parameters of body composition preventing diseases or injuries.

Most studies that address the assessment of pulmonary function in pregnant women, lists the studied parameters with age, height, race and body weight, in which was observed weak correlations. In this sense, knowing that the changes in body composition during pregnancy can have a negative impact on the health of pregnant women and that, there are only few studies that have considered the influence of body compartments in lung function, this study aims to give a better direction to studies that evaluate lung function and body composition in pregnant women, and this is our main contribution.

By correlating PEF and $\mathrm{FEF}_{25 \% 75 \%}$ with independent variables, it was noticed that the anthropometric and body composition variables showed an positive association, corroborating with the results of similar studies $[12,13,15,33]$. The data found in our study elucidated that age, height pre-pregnancy weight and the variables of body composition, except for the fat mass were positively correlated with $\mathrm{PEF}$ and $\mathrm{FEF}_{25 \% 75 \%}$, while the pre-pregnancy 
weight and body composition variables were associated with $\mathrm{FEF}_{25 \% 75 \%}$.

In order to investigate maximum peak flow values in pregnant women and to correlate it with BMI, age and maternal height, a study followed 26 pregnant women aged 16-36 years. It was observed that women with greater height and higher prepregnancy BMI had higher flows, indicating that these parameters can influence lung function [12].

From our findings, it is clear that lung function, $\mathrm{PEF}$ and $\mathrm{FEF}_{25 \% 75 \%}$ are correlated with anthropometric and body composition variables, and that these pass through several changes during the progression of pregnancy. Thus, it highlights the importance of developing more assertive strategies for the promotion of a pregnant woman's health, since an inadequate weight gain during the pregnancy cycle can negatively affect lung function.

In a multiple linear regression analysis was found that the height and maternal age were associated with PEF, being responsible for explaining $14.7 \%$ of its variability, while the pre-pregnancy weight

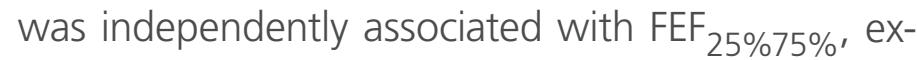
plaining $6.5 \%$ of its variability. Furthermore, it is clear that changes in lung function of low-risk and sedentary pregnant women are influenced by age and anthropometric data, and not by the variables of body composition. In this regard, it is emphasized the importance of the development of longitudinal studies in order to obtain more reliably aspects influencing changes in $\mathrm{PEF}$ and $\mathrm{FEF}_{25 \% 75 \%}$ in pregnant women.

\section{Conclusion}

Therefore, through the methodological control of procedures and representativeness of the sample, it can be considered that the results may represent the PEF behavior and $\mathrm{FEF}_{25 \% 75 \%}$ during a low-risk pregnancy, in the age range of 18-35 years.

Furthermore, corroborating the results presented in the literature, which show that the variables that influence lung flows refer to age, height and prepregnancy weight, it is concluded that the adaptations that occur in the endocrine, cardio-respiratory, musculoskeletal and nervous systems can preponderate over the changes in maternal body composition with the progress of pregnancy, maintaining lung function without harm to the mother and the fetus.

Thus, this result suggests that in healthy pregnant women with appropriate body weight, the PEF changes are associated with height and maternal age, as well as changes in $\mathrm{FEF}_{25 \% 75 \%}$ are associated with pre-pregnancy weight. It is noteworthy that no interference was observed in body composition of pregnant women, even measured by bioimpedance technology on the PEF and $\mathrm{FEF}_{25 \% 75 \% \text {. }}$

Whereas there are few studies with healthy pregnant women that take into account obstetric (GA and $\mathrm{FH}$ ) and body composition variables contributing to the changes in lung function, it is suggested the continuity of the study including, besides the group control, a longitudinal monitoring of pregnant women to better assess both variables of body composition and other obstetric characteristics that may influence lung function.

Another important aspect is the absence of normal ranges for the studied population; therefore, further studies are needed in order to build a pattern that serves as a reference, especially in the monitoring of pregnant women with respiratory diseases such as asthma or other complications that can compromise lung function.

\section{References}

1. Tan EK, Tan EL. Alterations in physiology and anatomy during pregnancy. Best Pract Res Clin Obstet Gynaecol. 2013; 27(6):791802.

2. LoMauro A, Aliverti A. Respiratory physiology of pregnancy. Breathe. 2015; 11(4):297-301.

3. Wise RA, Polito AJ, Krishnan V. Respiratory physiologic changes in pregnancy. Immunol Allergy Clin North Am. 2006; 26(1):1-12.

4. ACOG. Pulmonary disease in pregnancy. Int J Gynecol Obstet. 1996; 54:187-96. 
5. Pereira A, Krieger BP. Pulmonary complications of pregnancy. Clin Chest Med. 2004; 25(2):299-310.

6. Campbell DC. Physiological changes of pregnancy. Perioper Med Pain. 2000; 19(3):149-56.

7. Puranik BM, Kaore SB, Kurhade GA, Agrawal SD, Patwardhan SA, Kher JR. A longitudinal study of pulmonary function tests during pregnancy. Indian J Physiol Pharmacol. 1994; 38(2):12932.

8. Phatak MS, Kurhade GA. A longitudinal study of antenatal changes in lung function tests and importance of postpartum exercises in their recovery. Indian J Physiol Pharmacol. 2003; 47(3):352-6.

9. Fadia A, Dhadse M. A comparative study of static pulmonary function tests in Indian pregnant and non-pregnant women. International Journal of Research in Medical Sciences. 2016; 4(2):545-8.

10. Kolarzyk E, Szot WM, Lyszczarz J. Lung function and breathing regulation parameters during pregnancy. Arch Gynecol Obstet. 2005; 272(1):53-8.

11. Brancazio $L R$, Laifer $S A$, Schwartz T. Peak expiratory flow rate in normal pregnancy. Obstet Gynecol. 1997; 89(3):383-6.

12. Neppelenbroek GA, Mauad-Filho F, Cunha SP, Duarte G, Costa $A G$, Spara $P$, et al. Investigação do fluxo expiratório máximo em gestantes saudáveis. Rev Bras Ginecol. 2005; 27(16):37-43.

13. Puranik BM, Kurhade GA, Kaore SB, Patwardhan SA, Kher R. PEFR in pregnancy: a longitudinal study. Indian J Physiol Pharmacol. 1995; 39(2):135-9.

14. Singh S, Singh KC, Sircar SS, Sharma KN. Airway functions in pregnant indian women. Indian J Physiol Pharmacol. 1995; 39(2):160-2

15. Maiolo C, Mohamed El, Carbonelli MG. Body composition and respiratory function. Acta Diabetol. 2003; 40:32-8.

16. Engstrom JL, Sittler CP. Fundal height measurement. Part 1-Techniques for measuring fundal height. J Nurse Midwifery. 1993; 38(1):5-16

17. Renstrøm SBH, Andersen CS, Pedersen CHB, Madsen FF. Correct measurement of height is important when assessing lung function values. Dan Med J. 2012; 59(2):1-5

18. Thomson JL, Tussing-Humphreys LM, Goodman MH, Olender S. Baseline demographic, anthropometric, psychosocial, and behavioral characteristics of rural, southern women in early pregnancy. Matern Child Health J. 2016; 4:1-9

19. User's manual. InBody 720. Available in: $<$ https://sportedu.um.ac. ir/images/177/stories/pictures/azmayeshgah/manual/1inbody. $\mathrm{pdf}>$.

20. Kyle UG, Bosaeus I, De Lorenzo AD, Deurenberg P, Elia M, Gómez, JM, et al. Bioelectrical impedance analysis- Part II: Utilization in clinical practice. Clin Nutr. 2004; 23(6):1430-53.

21. Miller MR, Hankinson J, Brusasco V, Burgos F, Casaburi R, Coates A, et al. Standardisation of spirometry. Eur Respir J. 2005; 26(2):319-38.

22. Pereira CA de C. Espirometria. J Pneumol. 2002; 28(10):1-82.
23. Gee JB, Packer BS, Millen JE, Robin ED. Pulmonary mechanics during pregnancy. J Clin Invest. 1967; 46(6):945-52.

24. Liberatore SM, Pistelli R; Patalano F, Moneta E, Incalzi RA, Ciappi G. Respiratory function during pregnancy. Respiration. 1984; 46:145-50

25. Monga $U$, Kumari K. Pulmonary functions in punjabi pregnant women. Indian J Physiol Pharmacol. 2000; 44(1):115-6.

26. Teli A, Bagali S, Aithala M. A study of FVC, PEFR and MEP in different trimesters of pregnancy. Int J Biomed Adv Res. 2012; $3(8): 648-52$

27. Widen EM, Gallagher D. Body composition changes in pregnancy: measurement, predictors and outcomes. Eur J Clin Nutr. 2014; 68:643-52

28. Castro LC, Avina RL. Maternal obesity and pregnancy outcomes. Curr Opin Obstet Gynecol. 2002; 14(6):601-6.

29. Morais AAC, Tavares GM, Pezzin AC, Moana AA, Galvão HP, Faintuch J. Avaliação da composição corporal em gestantes de termo. Rev Assoc Med Bras. 1997; 43(2):109-13.

30. Larciprete G, Valensise H, Vasapollo B, Altomare F, Sorge R, Casalino $\mathrm{B}$, et al. Body composition during normal pregnancy: reference ranges. Acta Diabetol. 2003; 40:225-32.

31. Valensise $H$, Andreoli A, Lello S, Magnani F, Romanini C, De Lorenzo A. Multifrequency bioelectrical impedance analysis in women with a normal and hypertensive pregnancy. Am J Clin Nutr. 2000; 72:780-3

32. Unterborn J. Pulmonary function testing in obesity, pregnancy, and extremes of body habitus. Clin Chest Med. 2001; 22(4):75967.

33. Hasnain AD, Ahmad F, Erum A, Ali AMA, Mansoor AMR, Syed MAA, et al. Variation of peak expiratory flow rate with body mass index in medical students of Karachi, Pakistan. International Archives of Medicine. 2015; 8(121):1-5.

Publish in International Archives of Medicine

International Archives of Medicine is an open access journal publishing articles encompassing all aspects of medical science and clinical practice. IAM is considered a megajournal with independent sections on all areas of medicine. IAM is a really international journal with authors and board members from all around the world. The journal is widely indexed and classified Q1 in category Medicine. 